\title{
Is screening for interferon retinopathy in hepatitis $C$ justified?
}

\author{
F M Cuthbertson, M Davies, M McKibbin
}

Br J Ophthalmol 2004;88:1518-1520. doi: 10.1136/bjo.2004.043968

\begin{abstract}
Background/aim: In the treatment of hepatitis C, the National Institute for Clinical Excellence advocates use of a combination of interferon alfa and ribavirin for selected patients. Retinopathy is a well recognised side effect of interferon therapy and is characterised by retinal haemorrhages, cotton wool spots, and macular oedema. The aim of this study was to document the incidence and natural history of the retinopathy in patients treated with a long acting (pegylated) interferon and ribavirin for hepatitis $C$ and to assess the need to screen for retinal complications.

Methods: All patients started on treatment from September 2002 to August 2003 were invited to participate in the study. The past medical and ocular history, visual symptoms, and the results of a full ophthalmological assessment performed 3 months after starting treatment were noted. Any patient with retinal changes was followed up at 3 month intervals until the changes resolved.

Results: Of the 25 patients examined, four had evidence of retinopathy including deep retinal haemorrhage and cotton wool spots. Two of the patients were diabetic and one hypertensive. None had any visual symptoms and in all four the retinopathy resolved while the patients completed their course of treatment.

Conclusions: The incidence of retinopathy with pegylated interferon is low. The retinal complications resolve while treatment is continued and are asymptomatic. This study does not support routine screening for retinopathy in patients treated with pegylated interferon and ribavirin for hepatitis C.
\end{abstract}

$\mathrm{H}$ epatitis $\mathrm{C}$ is a blood borne RNA virus that can cause chronic liver disease. In the United Kingdom, the National Institute for Clinical Excellence (NICE) ${ }^{1}$ advocates treatment with a combination of interferon alfa and ribavirin for patients with moderate to severe hepatitis $C$ infection. Treatment is recommended for all adults who have not had previous interferon alfa monotherapy, as well as for those who have had previous treatment leading to an initial response and have then relapsed.

Interferon associated retinopathy was first described in 1990 by Ikebe et al. ${ }^{2}$ Features include haemorrhages and cotton wool spots around the disc and through the posterior pole, optic disc hyperaemia, and macular oedema. ${ }^{34}$ In addition, fluorescein angiography may demonstrate poorly perfused areas of retina. ${ }^{34}$ The reported incidence of retinopathy as a side effect of interferon varies widely in the literature. There is some evidence to suggest that the incidence of the retinopathy may be dose dependent. ${ }^{4}$ Treatment regimens with subcutaneous doses of interferon varying from $3 \times 10^{6}$ units three times a week to $9 \times 10^{6}$ units six times a week have been used for the hepatitis viruses, with higher doses used in the treatment of various malignancies. ${ }^{56}$ Case series and reports have shown an increased incidence of retinopathy in patients on higher and more frequent doses. ${ }^{7}$

Recently, a long acting form of interferon alfa has been developed, known as pegylated or polyethylene glycol conjugated interferon. This drug has slower absorption, a reduced volume of distribution, and lower elimination rates, ${ }^{9}$ as well as showing a more sustained virological response. ${ }^{10}$ Plasma levels of the drug are kept more stable, with a lower peak level. The local treatment protocol in our area uses pegylated interferon in combination with ribavirin. This encompasses a dose of $1.5 \mu \mathrm{g} / \mathrm{kg}$ of pegylated interferon, with an average $70 \mathrm{~kg}$ person receiving $105 \mu \mathrm{g}$ per week. The dose of ribavirin used is also weight dependent with a total of $800 \mathrm{mg}$ split over the day for people weighing $30-64 \mathrm{~kg}$, $1000 \mathrm{mg}$ for $65-86 \mathrm{~kg}$, and $1200 \mathrm{mg}$ over $86 \mathrm{~kg}$.

There are no previous reports in the literature relating to the incidence and severity of ocular side effects in patients treated with this regimen. Given the apparent dose dependent nature of interferon associated retinopathy and the altered pharmacokinetics of pegylated interferon, the aims of this study were to document the incidence and natural history of interferon associated retinopathy, to record any associated visual symptoms or systemic conditions, and to assess whether screening for this complication would be worthwhile.

\section{METHODS}

Patients started on combination treatment with pegylated interferon and ribavirin for hepatitis $\mathrm{C}$ during the study period were referred for ophthalmic examination by the hepatology team. Patients were normally examined by an ophthalmologist (FC) as close to 3 months after starting their treatment as possible. Patients with new visual symptoms were also seen sooner. Those patients with evidence of retinopathy at the 3 month stage were followed up at 3 month intervals until the retinopathy resolved. No changes to the interferon and ribavirin treatment regimen were made for these patients.

Full ocular and past medical histories were taken, and ocular examination was performed. This consisted of visual acuity assessment, slit lamp examination, applanation tonometry, and dilated fundal examination. Fundal photographs to document any abnormal findings were taken where appropriate. Full blood count parameters, blood pressure, and viral genotype were also recorded.

\section{RESULTS}

Between August 2002 and August 200332 patients were referred for screening, of whom 25 attended for ophthalmic assessment. All the patients were on treatment with pegylated interferon alfa and ribavirin according to the local protocol. There were 15 men and 10 women, with ages ranging from 26 to 73 years (see table 1). Of the seven 


\begin{tabular}{|c|c|c|c|c|c|c|c|}
\hline Patient no & Age & Sex & $\begin{array}{l}\text { Full blood count } \\
\text { abnormalities }\end{array}$ & Hypertension & Diabetes & Viral genotype & Retinopathy \\
\hline 1 & 33 & M & None & No & No & $3 a$ & No \\
\hline 2 & 38 & $\mathrm{~F}$ & Low $\mathrm{Hb}$ & No & No & 1 & No \\
\hline 3 & 53 & $M$ & None & No & No & $\mathrm{lb}$ & No \\
\hline 4 & 42 & M & None & No & No & $3 a$ & No \\
\hline 5 & 44 & M & None & No & No & $3 a$ & No \\
\hline 6 & 29 & M & Low platelets & No & No & la & No \\
\hline 7 & 43 & $\mathrm{~F}$ & None & No & No & $3 a$ & No \\
\hline 8 & 49 & M & Low platelets, low WCC & No & No & $3 a$ & No \\
\hline 9 & 30 & M & None & No & No & $3 a$ & No \\
\hline 10 & 60 & $\mathrm{~F}$ & None & No & Yes & 2 & Yes, both eyes \\
\hline 11 & 40 & M & None & No & No & la & No \\
\hline 12 & 48 & M & None & No & No & $3 a$ & No \\
\hline 13 & 40 & $\mathrm{~F}$ & Low WCC & No & No & 1 & No \\
\hline 14 & 34 & M & Low platelets & Yes & No & 1 & No \\
\hline 15 & 31 & $\mathrm{~F}$ & Low $\mathrm{Hb}$ & No & No & 2 & No \\
\hline 16 & 48 & $\mathrm{~F}$ & None & No & No & 2 & No \\
\hline 17 & 59 & $\mathrm{~F}$ & None & No & Yes & 1 & Yes, both eyes \\
\hline 18 & 50 & $\mathrm{~F}$ & Low $\mathrm{Hb}$, low $\mathrm{WCC}$ & Yes & No & $3 a$ & Yes, both eyes \\
\hline 19 & 26 & M & None & No & No & $3 a$ & Yes, left eye \\
\hline 20 & 53 & $\mathrm{~F}$ & None & No & No & $3 a$ & No \\
\hline 21 & 49 & M & None & No & No & $3 a$ & No \\
\hline 22 & 51 & M & Low $\mathrm{Hb}$ & Yes & No & $\mathrm{lb}$ & No \\
\hline 23 & 40 & M & None & No & No & $3 a$ & No \\
\hline 24 & 32 & M & None & No & No & 3 & No \\
\hline 25 & 73 & $\mathrm{~F}$ & None & Yes & No & $1 b$ & No \\
\hline
\end{tabular}

$\mathrm{Hb}$, haemoglobin; WCC, white cell count.

patients who did not attend for ophthalmological assessment, one died, two had their treatment stopped for unrelated reasons, and four failed to attend despite a number of appointments being offered.

At the 3 month examination, four of the 25 patients (16\%) had evidence of retinopathy consisting of cotton wool spots and/or haemorrhages (fig 1). This was bilateral in three patients and unilateral in one. None of these patients had macular oedema, disc changes or visual symptoms. Of the patients reporting visual symptoms, none of these were attributable to interferon retinopathy.

Diabetes mellitus was present in two of the 25 patients examined, both of whom had retinopathy. Systemic hyper- tension was present in four of the 25 patients, but only one had retinopathy. Full blood count abnormalities (haemoglobin $\leqslant 10 \mathrm{~g} / \mathrm{dl}$, white cell count $\leqslant 4$ or platelets $\leqslant 100$ ) were present in eight out of the 25 patients, only one of whom developed retinopathy. At the time of the 3 month examination when the retinopathy was noted, both the haemoglobin and platelets were back within normal limits. In the 25 patients examined, the most common viral genotype was $3 a$. The genotypes of the hepatitis $C$ virus in affected patients were type 1 in one patient, type 2 in one patient, and type $3 a$ in the remaining two.

For the four patients with retinopathy at the 3 month visit, further visits were arranged. After an additional 3 months
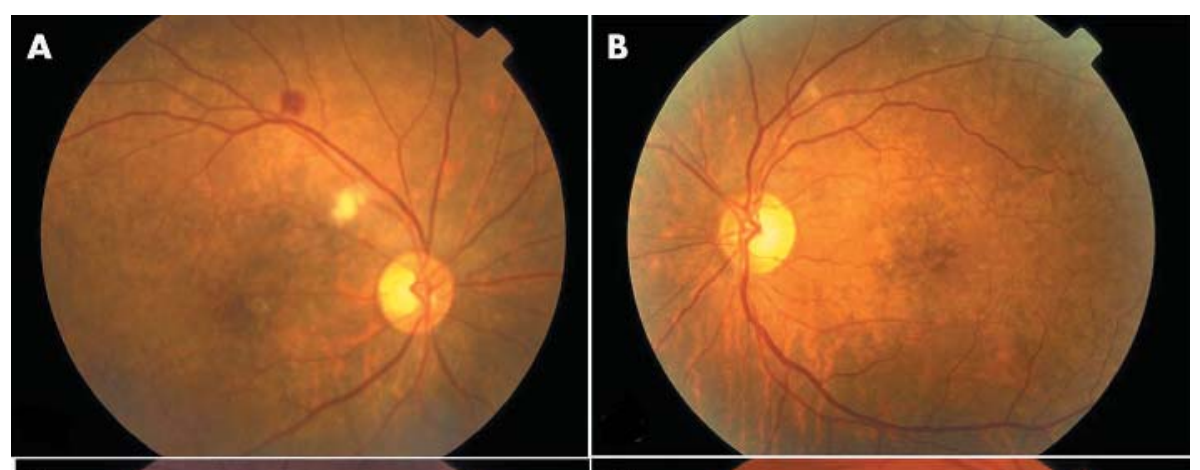

Figure 1 Retinopathy seen in patient 1 $(A, B)$, patient 2 (C), and patient $3(D)$.

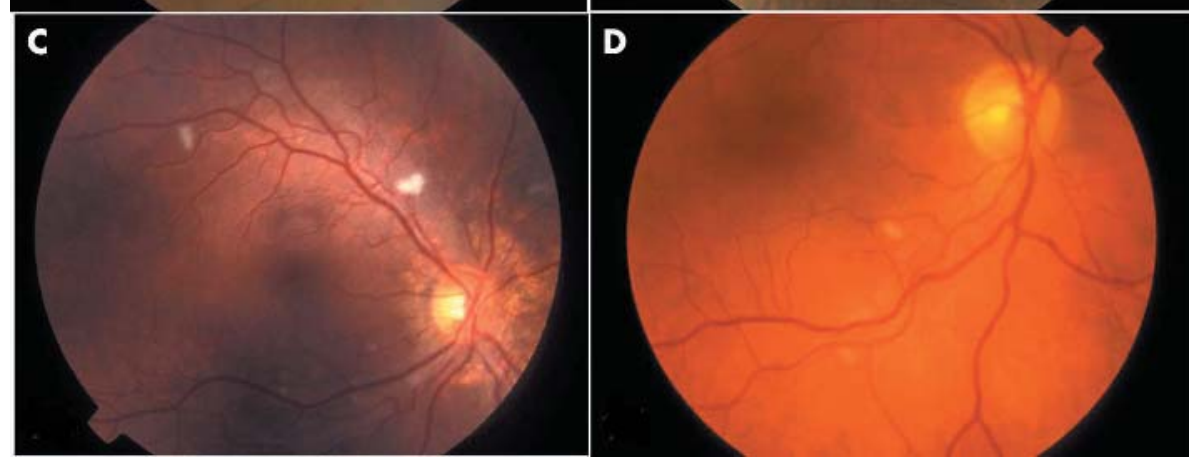


the retinopathy had disappeared in all patients except one, whose retinopathy had gone by 9 months after the initiation of treatment. All patients completed their planned courses of treatment without any dosage alteration.

\section{DISCUSSION}

Ocular side effects are well recognised complications of interferon and ribavirin therapy for hepatitis $\mathrm{C}$, with the most common of these being an ischaemic retinopathy characterised by haemorrhages and cotton wool spots. Other features include optic disc hyperaemia and macular oedema.

The incidence of reported retinopathy in patients on treatment with interferon for hepatitis viruses in the literature is very variable, with figures from fairly small scale studies ranging from $18 \%$ to $86 \% .{ }^{4}{ }^{71-18}$ Some of these studies have suggested that the retinopathy may be dose dependent or more common in patients with diabetes, ${ }^{4}$ hypertension, ${ }^{13}$ and abnormal full blood count parameters. It is notable that many of the previous studies looking at incidence of retinopathy were carried out with patients on high doses of interferon ranging from $6 \times 10^{6}$ to $10 \times 10^{6}$ units three times a week, which would be associated with high peak concentrations in tissues. Previous recommended treatment protocols have been based on the use of standard interferon alfa with ribavirin. They suggest that all patients receive 6 months of treatment initially, with a further 6 months offered to those with the type 1 viral genotype who have shown a good initial response to treatment with clearance of the virus. The dose of interferon used in standard treatment is 3 million $\left(3 \times 10^{6}\right)$ units subcutaneously three times a week. Following the recent availability of pegylated interferon, local treatment protocols have been adapted to use this. The advantages include less frequent injections, improved bioavailability but a lower total dose.

The incidence of retinopathy in our patient population was four out of $25(16 \%)$, which is lower than in any of the previously published studies. None of the four patients with retinopathy were symptomatic. In each case, the retinopathy resolved without long term sequelae. No patient had premature termination or alteration of their treatment regimen. Looking at the possible risk factors for developing interferon associated retinopathy, the presence of diabetes mellitus and systemic hypertension in this and other studies is similar. In this study, both the diabetic patients developed retinopathy but the number of cases is small. We found no convincing association of retinopathy with abnormal full blood count parameters or viral genotype.

Although the incidence of interferon associated retinopathy may be dose dependent, the exact mechanism by which this retinopathy develops remains unknown. The similarity of the clinical features to diabetic and hypertensive retinopathy suggests an ischaemic mechanism. Others have suggested that the deposition of immune complexes in the retinal vasculature leads to capillary non-perfusion and the formation of cotton wool spots. ${ }^{5}$

By carrying out just one basic screening assessment at 3 months after starting the treatment it could be argued that there is potential to miss patients with retinal changes. Previous case series have commented on the time of onset of retinopathy in relation to the start of treatment. Most report onset of the retinopathy in the first 8-12 weeks following the start of treatment ${ }^{411} 1920$ with just a few noticing retinopathy later. Our feeling was that there was sufficient evidence in previous studies to point to the most likely time for retinopathy to develop as being within the first 3 months, and that any earlier complications were unlikely to have resolved by then. It would theoretically be possible to miss earlier retinopathy that had remained asymptomatic and had resolved by the 3 month visit, but this is not likely to be of any clinical significance. Changes at a later date with a normal 3 month examination were unlikely.

This study confirms previous reports that retinopathy is a temporary and asymptomatic complication of interferon therapy, but suggests that the incidence of retinopathy with pegylated interferon is less than with standard interferon. As there are no visual symptoms or sequelae, we feel that routine screening for interferon associated retinopathy is not justified.

\section{Authors' affiliations}

F M Cuthbertson, M Davies, M McKibbin, St James University Hospital, Beckett Street, Leeds LS9 7TF, UK

Correspondence to: Fiona M Cuthbertson, St James University Hospital, Beckett Street, Leeds LS9 7TF, UK; fcuthbertson@hotmail.com

Accepted 5 April 2004

\section{REFERENCES}

1 Dillon A. Guidance on the use of ribavirin and interferon alpha for hepatitis C. October 2000, from the National Institute of Clinical Excellence. www.nice.org.uk/article.asp?a $=11676$

2 Ikebe T, Nakatsuka K, Goto M, et al. A case of retinopathy induced by intravenous administration of interferon. Folia Ophthalmol Jpn (Ganka-Kiyo) 1990;41:2291-6

3 Tu KL, Bowyer J, Schofield K, et al. Severe interferon associated retinopathy. Br J Ophthalmol 2003;87:247-8.

4 Hayasaka S, Nagaki $Y$, Matsumoto $M$, et al. Interferon associated retinopathy. $\mathrm{Br} J$ Ophthalmol 1998;82:323-5.

5 Guyer DR, Tiedemann J, Yannuzzi LA, et al. Interferon-associated retinopathy. Arch Ophthalmol 1993;111:350-6.

6 Esmaeli B, Koller C, Papedopoulos N, et al. Interferon-induced retinopathy in asymtomatic cancer patients. Ophthalmology 2001;108:858-60.

7 Hayasaka S, Fujii M, Yamamoto Y, et al. Retinopathy and subconjunctival haemorrhage in patient with chronic viral hepatitis receiving interferon alfa. Br J Ophthalmol 1995;79:150-2

8 Hayasaka S, Okada M, Yamamoto S. Retinopathy in chronic hepatitis C patients treated by systemic interferon alfa-2b. J Rev Clin Ophthalmol (Ganka Rinsho tho) 1996:90:1264-6.

9 Lake-Bakaar G. Current and future therapy for chronic hepatitis $C$ virus liver disease. Curr Drug Targets Infect Disord 2003;3:247-53.

10 Medina J, Garcia BL, et al. Therapeutic advantages of pegylation on interferon alpha in chronic hepatitis C. Rev Esp Enferm Dig 2003;95:568-74, 561-7.

11 Kawano T, Shigehira M, Woo H, et al. Retinal complications during interferon therapy for chronic hepatitis C. Am J Gastroenterol 1996;91:309-13.

12 Jain K, Lam WC, Waseeb S, et al. Retinopathy in chronic hepatitis $C$ patients during interferon treatment with ribavirin. Br J Ophthalmol 2001;85:1171-3.

13 Saito $\mathrm{H}$, Ebinuma $\mathrm{H}, \mathrm{Nagata} \mathrm{H}$, et al. Interferon-associated retinopathy in a uniform regimen of natural interferon-alpha therapy for chronic hepatitis $C$. Liver 2001;21:192-7.

14 Takikawa H, Kawakubo $\mathrm{H}$, Yuzawa $M$, et al. Interferon associated retinopathy induced by interferon $\beta$. Ganka 1994;36:189-93.

15 Seki $K$, Itou $Y$, Nishi $Y$, et al. Interferon therapy for type $C$ chronic active hepatitis and retinal haemorrhage. Acta Hepatol Jpn 1993;34:385-91.

16 Soushi S, Kobayashi F, Obazawa H, et al. Evaluation of risk factors of interferon-associated retinopathy in patients with type $C$ chronic active hepatitis. J Jpn Ophthalmol Soc (Nichigan Kaishi) 1996;100:69-76.

17 Kadayifcilar S, Boyacioglu S, Kart H, et al. Ocular complications with highdose interferon alpha in chronic active hepatitis. Eye 1999;13:241-6.

18 Chuman T, Nao-i N, Sawada A, et al. Interferon-induced retinal changes. Nippon Ganka Gakkai Zasshi 1994;98:616-21.

19 Sugano S, Yanagimoto M, Suzuki T, et al. Retinal complications with elevated circulating plasma $\mathrm{C} 5 \mathrm{a}$ associated with interferon- $\alpha$ therapy for chronic active hepatitis C. Am J Gastroenterol 1994;89:205-6.

20 Manesis E, Moschol M, Borouzas D, et al. Neurovisual impairment: a frequent complication of alpha-interferon treatment in chronic viral hepatitis. Hepatology 1998;27:1421-7. 